\title{
Assessment of emergency room cycle time in a tertiary hospital in Egypt
}

*Mahi M. Al-Tehewy, *Ihab S. Habil , *Nayera. S. Mostafa and **Mohammed N. Mansour

*Department of Community, Environmental and Occupational Medicine, Faculty of Medicine, Ain Shams University

**Quality Consultant.TQM AUC Instructor.

Received August 2015, accepted November 2015

\begin{abstract}
Timeliness of care is a critical element in the emergency room (ER) care process. The purpose of this study is to evaluate the timeliness of the emergency room cycle time which is measured from patient registration till patient disposition in a tertiary hospital in Egypt. Method: The ER cycle time was tracked by direct observation and by using a data collection sheet. Results: The results showed that the longest phase was the initial physician assessment with a median of 16 minutes and interquartile range of 47 minutes. While the shortest phase was the registration phase with a median of 2 minutes and interquartile range of 2 minutes. The total ER cycle time had a median of 37 minutes and interquartile range of 60 minutes. The time to physician assessment in different categories of patient severity by Canadian Triage and Acuity Scale (CTAS) was noted to meet target duration for each category of the CTAS. Also $30.6 \%$ of patients experienced nursing assessment in less than 2 minutes, $28.6 \%$ of patients experienced physician assessment in less than 4 minutes, $35.5 \%$ of patient experienced their disposition in less than 2 minutes and $26.8 \%$ of patients experienced their total ER cycle time between 38-80 minutes.
\end{abstract}

Keywords: Emergency Room, Cycle Time, Hospital Setting, Egypt.

*corresponding author, Email: al_tehewy@yahoo.com

\section{Introduction:}

According to the American College of Emergency Physicians (ACEP) Board of Directors ${ }^{(1)}$,Emergency medicine is the medical specialty dedicated to the diagnosis and treatment of unforeseen illness or injury. The practice of emergency medicine includes the initial evaluation, diagnosis, treatment, coordination of care among multiple providers, and disposition of any patient requiring expeditious medical, surgical, or psychiatric care. Emergency medicine is not defined by location, but may be practiced in a variety of settings including hospital-based and freestanding emergency departments (EDs), urgent care clinics, observation medicine units, emergency medical response vehicles, at disaster sites, or via telemedicine.

Waiting for treatment can be frustrating given that time is unproductively spent and according to Katzman ${ }^{(2)}$, people are impatient and do not want to wait to be attended to. While Cayirli et $\boldsymbol{a l}^{(3)}$, suggests that hospital managers and 
policy-makers are becoming more and more concerned with patient waiting time because it is a measure of organizational efficiency.

Poor ED throughput has been linked to the following patient and provider-related outcomes: increased morbidity and mortality, increased ED financial risk secondary to the loss or revenue from patients who left without being seen (LWBS), higher malpractice risk, and lower patient/provider satisfaction scores (4).

Emergency department (ED) waiting times have a serious impact on patient mortality, morbidity with readmission in less than 30 days, length of stay, and customer satisfaction. A review of the literature bears out the logical premise that since the outcome of treatment for all diseases and injuries is time-sensitive, the sooner treatment is rendered, the better the outcome ${ }^{(5)}$.It is clear from the literature that untimely hospital deaths and morbidity can be reduced by reductions in ED waiting times ${ }^{(6)}$.

According to National Quality Forum $(\mathrm{NQF})^{(7)}$, the emergency room cycle time was used in their quality measures as "The Median time from emergency department arrival to time of departure from the emergency room".

The Pennsylvania Patient Safety Advisory $^{(8)}$, defines Waiting time in the ER or "Door to Doctor time" as "the median time (in minutes) from first contact in the ED to the time that the patient sees qualified medical personnel for the first time for evaluation and management of the medical condition", also referred to as "the patient arrival in the ED to diagnostic evaluation phase".
Keith et al ${ }^{(9)}$, used direct observation to collect patient flow data on 1,728 patients at multiple ED sites in Saskatchewan, Canada. The total ED transit time ranged from 2 hours for the lowest acuity patients to $6 \frac{1}{2}$ hours for those with highest acuity. The average transit time was nearly 5 hours. Overall, approximately one-half of total ED transit time is spent waiting. Higher acuity patients had longer transit times but wait far less.

A substantial number $(85 \%)$ of respondents to a survey of Canadian ED directors indicated inpatient bed unavailability was the principal cause to ED over crowding ${ }^{(10)}$. Additional studies have reiterated the assertion that flow problems associated with admitted patients from the ED to the hospital leads to substantial congestion difficulties ${ }^{(11-}$ $15)$.

A number of viable interventions designed to improve ED patient flow have appeared in the literature. These represent potential improvement initiatives that could be used by any ED facility desiring to reduce wait times. $\mathbf{N g}$ (16), adopted certain process adjustments such as locating clearly-marked supplies and equipment in the right places, standardizing the organization of charts, and using treat and release area nurses to "pull" the patients as soon as an inpatient bed was available. Jacobsen and $\boldsymbol{R e s a r}^{(17)}$, suggest that hospitals orchestrate an inpatient's discharge earlier in the overall process. This would help to reduce the time interval associated with admitting an ED patient to a hospital bed. Haraden and Resar (18), advocate the use of inpatient bed discharge slots, so patients would spend less time waiting in the ED for a hospital bed. Blake et al ${ }^{(19)}$, developed a computer simulation model 
to show that increasing physician coverage hours at certain times in the ED would lead to reduced wait times.

This current study was conducted to determine the emergency room cycle time in a tertiary hospital. And to describe some factors affecting Emergency Room cycle time.

\section{Study Design and Methods}

Study setting; the study was conducted in Egypt Air hospital; a tertiary private referral hospital with 210 beds. The emergency room in the studied hospital has 12 beds, and operated by 25 nurses and 12 physicians. There is no triage system in place in the ER.

This observational study was conducted in the $3^{\text {rd }}$ quarter of 2013 by direct observation of all legible Patients attending emergency rooms in the selected hospital with exceptions to cases of death on arrival, mass causality defined by Mistovich $\boldsymbol{e t} \boldsymbol{a l}^{(20)}$, as any incident in which emergency medical services resources, such as personnel and equipment, are overwhelmed by the number and severity of casualties, and cases referred to emergency room to have non-emergency services e.g. dressing change, ECG request from Out Patient Department...etc.

Using a data collection sheet developed to track the timeliness of each step of patient journey inside emergency room including the following items; gender, age, time, shift, acuity Level (Based on the Canadian Triage and Acuity Scale (CTAS)), investigations required (Lab and Radiology), consultations, time of registration, triage time, nursing assessment time, physician assessment time, time of physician decision, time of patient disposition. A sample estimated to be 140 subjects per hospital was observed. The alpha error was set to be $5 \%$ and power $80 \%$.

In addition to the patient data collection sheet, a shift data collection sheet was also used to capture the changing variables per shift in the hospital including the following items; shift time, shift date, total number of physicians available and their level of education and training, total number of nurses available and their level of education and training, total number of nurse aids/porters available, occupancy rate of the day, total number of available stretchers.

The hospital had no triage process so the researcher had to triage cases by himself (A physician and Certified European Council Advanced Cardiac Life Support provider) by applying Canadian Triage and Acuity Scale Criteria.

Data Management phase started by data cleaning then data entry using a personal computer and finally data were analyzed using Statistical Package for Social Science (SPSS) version 20. Qualitative data were presented in frequency and percentage. Quantitative data were presented by mean and standard deviation; in case of skewed data, the median and interquartile range were used. Comparison of qualitative data was done using Chi-square test. Comparison of quantitative data was done using the $t$ test for independent samples or the Mann Whitney test for the data that are not following the normal distribution. "P" value of 0.05 was chosen as level of significance.

The whole ER cycle time was measured along with the details of every phase of patient journey in the ER. The data was analyzed in relation to different patients' 
demographics and level of triage upon their entry to ER.

\section{Results}

According to Table (1) the total number of patients observed was 140 cases. The average age of patients was 43.4 years with a standard deviation of \pm 18.06 years. The percentage of males was higher than females representing $65.7 \%$ of the study population. The total number of discharged patients was 113 which represented a percentage of $81.9 \% .21 \%$ of patients needed consultations while $51.4 \%$ of them needed diagnostic investigations.

As seen in Figure (1)the patient journey inside the ER followed this sequence; registration, initial nursing assessment, initial physician assessment, physician decision and patient disposition. And it's worthy noticing that there is no triage system applied in the ER of the studied hospital.

Table (2)shows that the longest phase was the initial physician assessment with a median of 16 minutes and interquartile range of 47 minutes. While the shortest phase was the registration phase with a median of 2 minutes and interquartile range of 2 minutes. The total ER cycle time had a median of 37 minutes and interquartile range of 60 minutes. Also the median time for consultations was 11 minutes while the median time for investigations was 78.5 minutes.

Also the data shows that $30.6 \%$ of patients experienced nursing assessment in less than 2 minutes. $28.6 \%$ of patients experienced physician assessment in less than 4 minutes. $35.5 \%$ of patient experienced their disposition in less than 2 minutes. $26.8 \%$ of patients experienced their total ER cycle time between 38-80 minutes.

No significant statistical difference was noted between vacation / working days and different shifts in quartile distribution of the durations of each step in the studied hospital Tables $(\mathbf{3}, \mathbf{4})$.

Also no significant statistical difference between patients gender (Male/Female) was noted in quartile distribution of the durations of each step in the studied hospital except in the step of physician assessment Table (5).

\section{Limitations}

The study couldn't track patients' outcomes after being admitted, transferred or discharged so shorter patient stay durations were not verified to have positively impacted patients or not. Since data collection was carried on by the researcher only, it stopped during few researcher's breaks. The staff of the hospital were uncomfortable for the presence of the researcher at the beginning of the data collection phase as he was perceived by them as performing quality control audit over their work and sometimes the staff feeling threatened by the researcher presence followed the ideal procedure instead of their daily routine practice but as researcher gained leadership approval and the commitment of ER manager prior to the study this helped the researcher to overcome this obstacle and complete the study.

\section{Discussion}

The characteristics of the emergency room of the hospital show that the total number of nurses was 25 , the number of physicians was 12 and the number of ER beds was 12, the American Academy for Emergency medicine $(\boldsymbol{A A E M})^{(21)}$, stated 
that the emergency physician staffing ratio should be based on the rate of patient influx such that the rate of 2.5 patients per physician per hour is not exceeded and the minimum emergency nurse-to-patient staffing ratio should be $1: 3$ or based on the rate of patient influx such that the rate of 1.25 patients per nurse per hour is not exceeded. In addition, dedicated triage and charge nurses are necessary in higher volume departments.

Based on the AAEM ratios and number of ER beds it was estimated that the hospital should have at minimum per shift 5 nurses and 3 physicians which are close numbers to the average staff per shift identified in the hospital during the study period.

The sequence of steps identified in the hospital during the study period started with registration then initial nursing assessment then initial physician assessment followed by physician taking decision then patient disposition and this sequence is in line with Yoon $^{(22)}$,who classified ED cycle time into the following stages 1) from ED entry (registration) to triage assessment, 2) from triage assessment to nursing assessment, 3) from nursing assessment to physician assessment, 4) from physician assessment to disposition decision (i.e., admission vs. discharge), and 5) from disposition decision to actual departure from the ED. However Triage step was missing in the studied hospital.

It was noted also that time to physician assessment in different categories of patient severity by Canadian Triage and Acuity Scale (CTAS) met target duration for each category.

A study by Keith et $\boldsymbol{a l}^{(9)}$, used direct observation to collect patient flow data on 1,728 patients at multiple ED sites in
Saskatchewan, Canada concluded that higher acuity patients had longer transit times but wait far less while Canadian Triage Acuity Scale (CTAS 1) patients requiring immediate resuscitation spent almost none of their transit time waiting. The average initial wait time (from the completion of triage until the patient is placed in an ED bed). The most acute patients spend very little, if any, time waiting to be placed into a bed. CTAS 4 and 5 patients, on the other hand, have considerably longer waits during this part of their ED visit.

The longest phase of patient journey inside the ER was the initial physician assessment with a median of 16 minutes and interquartile range of 47 minutes. While the shortest phase was the registration phase with a median of 2 minutes and interquartile range of 2 minutes. The total ER cycle time had a median of 37 minutes and interquartile range of 60 minutes. And data shows that $30.6 \%$ of patients experienced nursing assessment in less than 2 minutes. $28.6 \%$ of patients experienced physician assessment in less than 4 minutes. $35.5 \%$ of patient experienced their disposition in less than 2 minutes. $26.8 \%$ of patients experienced their total ER cycle time between $38-80$ minutes.

According to Canadian Institute for Health Information $^{(23)}$,the median length of stay in emergency departments measured from the time of registration or triage to the time of ED discharge was approximately 2 hours (128 minutes). However, $10 \%$ of patients spent 36 minutes or less (10th percentile) and $10 \%$ spent over six hours in the ED (90th percentile) in 2003-2004. The amount of time that patients spent in the ED varied according to the severity of their illness, the patients' age, how many other 
patients were being cared for and the time of the day the visit took place.

In a study conducted by $\boldsymbol{R e h m a n i}^{(24)}$, exploring reasons of overcrowding in a university hospital ER section of Karachi, Pakistan it was found that about two-third of all delays were due to unavailability of bed, followed by financial constraints, involvement of multiple specialty, and because the admitting residents wanted to investigate the patients more thoroughly.

$21 \%$ of patients needed consultations while $51.4 \%$ of patients were ordered investigations by their physicians. The median time for consultations was 11 minutes while the median time for investigations was 78.5 minutes. One of the causes of overcrowding in ER identified also by $\boldsymbol{R e h m a n i}^{(24)}$, in his study was the admitting residents wanted to investigate the patients more thoroughly.

Tashkandy et $\boldsymbol{a l}^{(25)}$, conducted a study in Al-Noor hospital; this study highlighted the reasons which contributed to longer stay of patients in Emergency Department (ED) who were advised admission. Common reasons for delay included; multiple consultations with further investigations and file making process.

The most common decision taken by the ER physician was to discharge patients home $(81.9 \%)$ and this is consistent with the study of Keith $\boldsymbol{e t} \boldsymbol{a l}^{(9)}$, that showed $92.8 \%$ of the patient population was destined to a physician disposition decision of discharge.

No significant statistical difference was noted regarding the effect of working days versus days of vacation over the durations of different steps in the studied hospital. And this may be attributed to the non-routine nature of the services provided in the ER which do not abide by the regular patterns of other nonemergency service providing departments.

No significant statistical difference between patients gender (Male/Female) in quartile distribution of the durations of each step in the studied hospital except in the step of physician assessment.

Also no significant statistical difference was noted in this study regarding the total ER cycle time among the three shifts of the ER.

\section{Conclusion}

The staffing pattern for physicians and nurses was compliant to the recommendations of the American academy for emergency medicine $\boldsymbol{( A A E M}^{(21)}$. The hospital was timely in meeting target durations for each category of Canadian Triage and Acuity sale. The Initial physician assessment was the longest among the steps of patient journey inside ER. Most of disposition decisions made by emergency room physicians are to discharge patients in both hospitals. Working days versus vacations did not impact patient ER cycle time pattern.

\section{Recommendations}

The hospital should start developing a triage system. And should keep its excellent performance in keeping the timeframes for different CTAS categories patients in line with the recommended durations.

\section{References}

\section{1) American College of Emergency Physicians (ACEP) Board of Directors.}


(2015). “ACEP Policy

Statements ; Definition of

Emergency Medicine";

available online;

http://www.acep.org/Clinical-

--Practice-

Management/Definition-of-

Emergency-Medicine/

2) Katzman C.N. (1999). "New

Jersey hospital works to satisfy customers", Modern Healthcare, 29(51):48.

3) Cayirli T., Veral E. and Rosen H. (2008). Assessment of patient classification in appointment system design, Production and Operations Management, Special Issue Vol. 17, No.3, pp. 338-353.

4) Joseph G. (2013).Cracking the code: fixing the crowded emergency department, part 1 -building the burning platform, Common Sense. Advances in Emergency Medicine 20(5):18-20.

5) Guttmann, A., Schull, M. J., Vermeulen, M. J. \& Stukel, T. A. (2013). "The relationship between emergency department crowding and patient outcomes: A systematic review". Journal of Nursing Scholarship 46(2)1.

6) Thomas A. Sharon. (2015). "Shortening Emergency Department Waiting Times through Evidenced-Based Practice". Locatible Health Tech Hub pp128-133.

7) National Quality Forum (NQF). (2008). "NQF endorses measures to address care coordination and efficiency in hospital emergency departments". Available at http://urgentmatters.org/medi a/file/NQF\%20Press\%20.Rel ease.pdf.

8) Pennsylvania Patient Safety Advisory. (2010). "Managing Patient Access and Flow in the Emergency Department to Improve Patient Safety Authority" 07(4):123-134.

9) Keith A. Willoughby, Benjamin T.B. Chan, Marlene Strenger. (2010). "Achieving wait time reduction in the emergency department", Leadership in Health Services 23(4):30419.

10) Canadian Agency for Drugs and Technologies in Health. (2006).

Emergency Department Overcrowding in Canada: What are the Issues and What can be Done? Ottawa, pp572-585.

11) Asplin, B.R. et al. (2003). "A conceptual model of emergency department crowding", Annals of Emergency Medicine, 42(2):173-80.

12) Espinosa, G. et al. (2002). "Effects of external and internal factors on emergency department overcrowding", Annals of Emergency Medicine 39(6):693-95.

13) Kellermann, A.L. (2000). "Déjà vu", Annals of Emergency Medicine 35(1):83-5.

14) Schull, M.J. et al. (2003). "Emergency department contributors to ambulance 
diversion: A quantitative analysis", Annals of Emergency Medicine 41(4): 467- 76.

15) Schull, M.J. et al. (2007). "The effect of low-complexity patients on emergency department waiting times", Annals of Emergency Medicine 49(3): 257-64.

16) Ng, D. (2006). "Hotel-Dieu Grace Hospital ER LEA(R)N project: Reducing ER wait times", Leadership in Health Services. Vol.23, Issue 4, pp1-30.

17) Jacobsen, D. and Resar, R. (2006). "Streamlining Discharges - Session 1: Expose the Gap", Institute for Healthcare Improvement presentation. 296(7):827-843.

18) Haraden, C. and Resar, R. (2006). "Streamlining the discharge: Using discharge appointments", Institute for Healthcare. The Joint Commission Journal on Quality and Patient Safety, Volume 32, Number 10, October, pp. 585-590(6)

19) Blake, J.T. et al. (1996). "An analysis of emergency room wait time issues via computer simulation", INFOR 34(4):263-73.

20) Mistovich, Joseph J. et al. (2000). "Brady Prehospital
Emergency Care Sixth Edition":866.

21) American Academy for Emergency Medicine. (2001). Position Statement on Nurse-to-Patient ED Staffing Ratios and Physician-toPatient ED Staffing Ratios. Accessed online in July 2015 at http://www.aaem.org/emresources/position.Pediatrics Vol.107, Issue 3, pp 330-34.

22) Yoon P. (2003). "Emergency Department Fast-Track System", University of Alberta and Alberta Heritage Foundation for Medical Research. Vol.13, Issue 1, pp 32-35.

23) Canadian Institute for Health Information. 2005, "Understanding Emergency Department Wait Times", Healthcare policy, Vol.10, pp 103-119.

24) Rehmani R. (2004). Emergency section and overcrowding in a university hospital of Karachi, Pakistan, the journal of the Pakistan medical association 54(5)2337.

25) Tashkandy MA, Gazzaz ZJ, Farooq MU, Dhafar KO. (2008). "Reasons for delay in inpatient admission at an emergency department". J Ayub Med CollAbbottabad; 20(1):38-42. 
Table 1. Characteristics of enrolled patients visiting the studied ER.

\begin{tabular}{|c|c|}
\hline \multicolumn{1}{|c|}{ Item } & Descriptives \\
\hline Total No. & $\mathbf{1 4 0}$ \\
\hline Age (Mean $\mathbf{\pm}$ SD) & $43.4 \pm 18.06$ \\
\hline Gender [No. (\%)] & \\
\hline Male & $90(65.7 \%)$ \\
\hline Female & $48(34.3 \%)$ \\
\hline Outcome [No. (\%)] & $113(81.9 \%)$ \\
\hline Discharged & $29(21 \%)$ \\
\hline Need consultations & $71(51.4 \%)$ \\
\hline Need investigations & \\
\hline
\end{tabular}

Table 2 The median (interquartile range) duration of different ER times in the studied hospital.

\begin{tabular}{|l|c|}
\hline \multicolumn{1}{|c|}{ ER Cycle } & $\begin{array}{c}\text { Duration in minutes } \\
\text { Median (Interquartile Range) }\end{array}$ \\
\hline Registration & $\mathbf{2 ( 2 )}$ \\
\hline Triage & - \\
\hline Nursing Assessment & $3(4)$ \\
\hline Physician Assessment & $16(47)$ \\
\hline Patient Disposition & $5(10)$ \\
\hline Total ER Cycle Time & $37(60)$ \\
\hline Consultation & $11(12.5)$ \\
\hline Investigation & $78.5(97.7)$ \\
\hline
\end{tabular}


Table 3. Comparing quartile distribution of ER steps' durations in vacation and working days in the studied hospital.

\begin{tabular}{|c|c|c|c|c|c|}
\hline ER Steps & \multicolumn{2}{|c|}{$\begin{array}{c}\text { Quartile Duration } \\
\text { (minutes) }\end{array}$} & $\begin{array}{c}\text { Vacation } \\
\mathbf{N}(\%)\end{array}$ & $\begin{array}{c}\text { Working } \\
\text { Days }\end{array}$ & $\begin{array}{c}\text { P- } \\
\text { Value }\end{array}$ \\
\hline \multirow{4}{*}{$\begin{array}{c}\text { Patient } \\
\text { Registration }\end{array}$} & 1st & $\leq 1$ & $5(26.32)$ & 46 (38.98) & \multirow[t]{4}{*}{0.661} \\
\hline & $2^{\text {nd }}$ & $2-2$ & $5(26.32)$ & $22(18.64)$ & \\
\hline & $3^{\text {rd }}$ & 3-4 & $4(21.05)$ & $27(22.88)$ & \\
\hline & $4^{\text {th }}$ & $5+$ & $5(26.32)$ & $23(19.49)$ & \\
\hline \multirow{4}{*}{$\begin{array}{c}\text { Nursing } \\
\text { Assessment }\end{array}$} & $1^{\text {st }}$ & $\leq 2$ & $5(31.25)$ & $29(30.53)$ & \multirow[t]{4}{*}{0.449} \\
\hline & $2^{\text {nd }}$ & 3-3 & $5(31.25)$ & $19(20.00)$ & \\
\hline & $3^{\text {rd }}$ & $4-5$ & $4(25.00)$ & 18 (18.95) & \\
\hline & $4^{\text {th }}$ & $6+$ & $2(12.50)$ & $29(30.53)$ & \\
\hline \multirow{4}{*}{$\begin{array}{c}\text { Physician } \\
\text { Assessment }\end{array}$} & $1^{\text {st }}$ & $\leq 4$ & $6(31.58)$ & $32(28.07)$ & \multirow[t]{4}{*}{0.488} \\
\hline & $2^{\text {nd }}$ & $5-17$ & $4(21.05)$ & $22(19.30)$ & \\
\hline & $3^{\text {rd }}$ & $18-59$ & $7(36.84)$ & $30(26.32)$ & \\
\hline & $4^{\text {th }}$ & $60+$ & $2(10.53)$ & $30(26.32)$ & \\
\hline \multirow{4}{*}{$\begin{array}{c}\text { Patient } \\
\text { Disposition }\end{array}$} & $1^{\text {st }}$ & $\leq 2$ & $3(15.79)$ & $46(38.66)$ & \multirow[t]{4}{*}{0.249} \\
\hline & $2^{\text {nd }}$ & $3-5$ & $8(42.11)$ & $32(26.89)$ & \\
\hline & $3^{\text {rd }}$ & 6-14 & $3(15.79)$ & $18(15.13)$ & \\
\hline & $4^{\text {th }}$ & $15+$ & $5(26.32)$ & $23(19.33)$ & \\
\hline \multirow{4}{*}{$\begin{array}{c}\text { Total ER } \\
\text { Cycle Time }\end{array}$} & $1^{\text {st }}$ & $\leq 16$ & $6(31.58)$ & $28(23.53)$ & \multirow[t]{4}{*}{0.707} \\
\hline & $2^{\text {nd }}$ & $17-37$ & $6(31.58)$ & $30(25.21)$ & \\
\hline & $3^{\text {rd }}$ & 38-80 & $4(21.05)$ & $33(27.73)$ & \\
\hline & $4^{\text {th }}$ & $81+$ & $3(15.79)$ & $28(23.53)$ & \\
\hline
\end{tabular}


Table 4. Comparing quartile distribution of ER steps' durations in different shifts in the studied hospital.

\begin{tabular}{|c|c|c|c|c|c|c|}
\hline ER Steps & \multicolumn{2}{|c|}{$\begin{array}{l}\text { Quartile Duration } \\
\text { (minutes) }\end{array}$} & $\begin{array}{l}\text { Shift A } \\
\text { N(\%) }\end{array}$ & $\begin{array}{l}\text { Shift B } \\
\text { N(\%) }\end{array}$ & $\begin{array}{l}\text { Shift C } \\
\text { N(\%) }\end{array}$ & $\begin{array}{c}\text { P- } \\
\text { Value }\end{array}$ \\
\hline \multirow{4}{*}{$\begin{array}{c}\text { Patient } \\
\text { Registration }\end{array}$} & $1^{\text {st }}$ & $\leq 1$ & $19(43.18)$ & $13(48.15)$ & 9 (16.07) & \multirow[t]{4}{*}{0.560} \\
\hline & $2^{\text {nd }}$ & $2-2$ & $9(20.45)$ & $3(11.11)$ & $15(26.79)$ & \\
\hline & $3^{\text {rd }}$ & 3-4 & $8(18.18)$ & $6(22.22)$ & $17(30.36)$ & \\
\hline & $4^{\text {th }}$ & $5+$ & $8(18.18)$ & $5(18.52)$ & 15 (26.79) & \\
\hline \multirow{4}{*}{$\begin{array}{c}\text { Nursing } \\
\text { Assessment }\end{array}$} & $1^{\text {st }}$ & $\leq 2$ & $9(31.03)$ & $6(24.00)$ & $19(33.33)$ & \multirow[t]{4}{*}{0.209} \\
\hline & $2^{\text {nd }}$ & 3-3 & $8(27.59)$ & $5(20.00)$ & $11(19.30)$ & \\
\hline & $3^{\text {rd }}$ & 4-5 & $9(31.03)$ & $4(16.00)$ & $9(15.79)$ & \\
\hline & $4^{\text {th }}$ & $6+$ & $3(10.34)$ & $10(40.00)$ & $18(31.58)$ & \\
\hline \multirow{4}{*}{$\begin{array}{c}\text { Physician } \\
\text { Assessment }\end{array}$} & $1^{\text {st }}$ & $\leq 4$ & $17(39.53)$ & $5(19.23)$ & $16(25.00)$ & \multirow[t]{4}{*}{0.070} \\
\hline & $2^{\text {nd }}$ & 5-17 & $6(13.95)$ & $3(11.54)$ & $17(26.56)$ & \\
\hline & $3^{\text {rd }}$ & 18-59 & $7(16.28)$ & $11(42.31)$ & 19 (29.69) & \\
\hline & $4^{\text {th }}$ & $60+$ & $13(30.23)$ & $7(26.92)$ & $12(18.75)$ & \\
\hline \multirow{4}{*}{$\begin{array}{c}\text { Patient } \\
\text { Disposition }\end{array}$} & $1^{\text {st }}$ & $\leq 2$ & $18(40.00)$ & $14(51.85)$ & $17(25.76)$ & \multirow[t]{4}{*}{0.190} \\
\hline & $2^{\text {nd }}$ & $3-5$ & $14(31.11)$ & $5(18.52)$ & $21(31.82)$ & \\
\hline & $3^{\text {rd }}$ & $6-14$ & $4(8.89)$ & $5(18.52)$ & $12(18.18)$ & \\
\hline & $4^{\text {th }}$ & $15+$ & $9(20.00)$ & $3(11.11)$ & $16(24.24)$ & \\
\hline \multirow{4}{*}{$\begin{array}{c}\text { Total ER } \\
\text { Cycle Time }\end{array}$} & $1^{\text {st }}$ & $\leq 16$ & $15(33.33)$ & $5(18.52)$ & $14(21.21)$ & \multirow[t]{4}{*}{0.443} \\
\hline & $2^{\text {nd }}$ & $\mathbf{1 7 - 3 7}$ & $9(20.00)$ & $8(29.63)$ & 19 (28.79) & \\
\hline & $3^{\text {rd }}$ & 38-80 & $13(28.89)$ & $5(18.52)$ & 19 (28.79) & \\
\hline & $4^{\text {th }}$ & $81+$ & $8(17.78)$ & $9(33.33)$ & $14(21.21)$ & \\
\hline
\end{tabular}


Table 5 Comparing quartile distribution of ER steps' durations in patients gender (Male/Female) in the studied hospital.

\begin{tabular}{|c|c|c|c|c|c|}
\hline ER Steps & \multicolumn{2}{|c|}{$\begin{array}{c}\text { Quartile Duration } \\
\text { (minutes) }\end{array}$} & $\begin{array}{l}\text { Male } \\
\mathbf{N}(\%)\end{array}$ & $\begin{array}{l}\text { Female } \\
\text { N }(\%)\end{array}$ & P-Value \\
\hline \multirow{4}{*}{$\begin{array}{c}\text { Patient } \\
\text { Registration }\end{array}$} & 1st & $\leq 1$ & 35 (39.33) & $16(33.33)$ & \multirow[t]{4}{*}{0.779} \\
\hline & $2^{\text {nd }}$ & $2-2$ & $18(20.22)$ & $9(18.75)$ & \\
\hline & $3^{\text {rd }}$ & $3-4$ & $20(22.47)$ & $11(22.92)$ & \\
\hline & $4^{\text {th }}$ & $5+$ & $16(17.98)$ & $12(25.00)$ & \\
\hline \multirow{4}{*}{$\begin{array}{c}\text { Nursing } \\
\text { Assessment }\end{array}$} & $1^{\text {st }}$ & $\leq 2$ & $25(36.23)$ & $9(21.43)$ & \multirow[t]{4}{*}{0.084} \\
\hline & $2^{\text {nd }}$ & 3-3 & $10(14.49)$ & $14(33.33)$ & \\
\hline & $3^{\text {rd }}$ & $4-5$ & $13(18.84)$ & $9(21.43)$ & \\
\hline & $4^{\text {th }}$ & $6+$ & $21(30.43)$ & $10(23.81)$ & \\
\hline \multirow{4}{*}{$\begin{array}{c}\text { Physician } \\
\text { Assessment }\end{array}$} & $1^{\text {st }}$ & $\leq 4$ & $18(20.93)$ & $20(42.55)$ & \multirow[t]{4}{*}{0.045} \\
\hline & $2^{\text {nd }}$ & $5-17$ & 17 (19.77) & $9(19.15)$ & \\
\hline & $3^{\text {rd }}$ & 18-59 & $26(30.23)$ & $11(23.40)$ & \\
\hline & $4^{\text {th }}$ & $60+$ & $25(29.07)$ & $7(14.89)$ & \\
\hline \multirow{4}{*}{$\begin{array}{c}\text { Patient } \\
\text { Disposition }\end{array}$} & $1^{\text {st }}$ & $\leq 2$ & $35(38.89)$ & $14(29.17)$ & \multirow[t]{4}{*}{0.312} \\
\hline & $2^{\text {nd }}$ & $3-5$ & $28(31.11)$ & $12(25.00)$ & \\
\hline & $3^{\text {rd }}$ & $6-14$ & $11(12.22)$ & $10(20.83)$ & \\
\hline & $4^{\text {th }}$ & $15+$ & $16(17.78)$ & $12(25.00)$ & \\
\hline \multirow{4}{*}{$\begin{array}{c}\text { Total ER } \\
\text { Cycle Time }\end{array}$} & $1^{\text {st }}$ & $\leq 16$ & $18(20.00)$ & $16(33.33)$ & \multirow[t]{4}{*}{0.379} \\
\hline & $2^{\text {nd }}$ & 17-37 & $25(27.78)$ & $11(22.92)$ & \\
\hline & $3^{\text {rd }}$ & 38-80 & $25(27.78)$ & $12(25.00)$ & \\
\hline & $4^{\text {th }}$ & $81+$ & $22(24.44)$ & $9(18.75)$ & \\
\hline
\end{tabular}

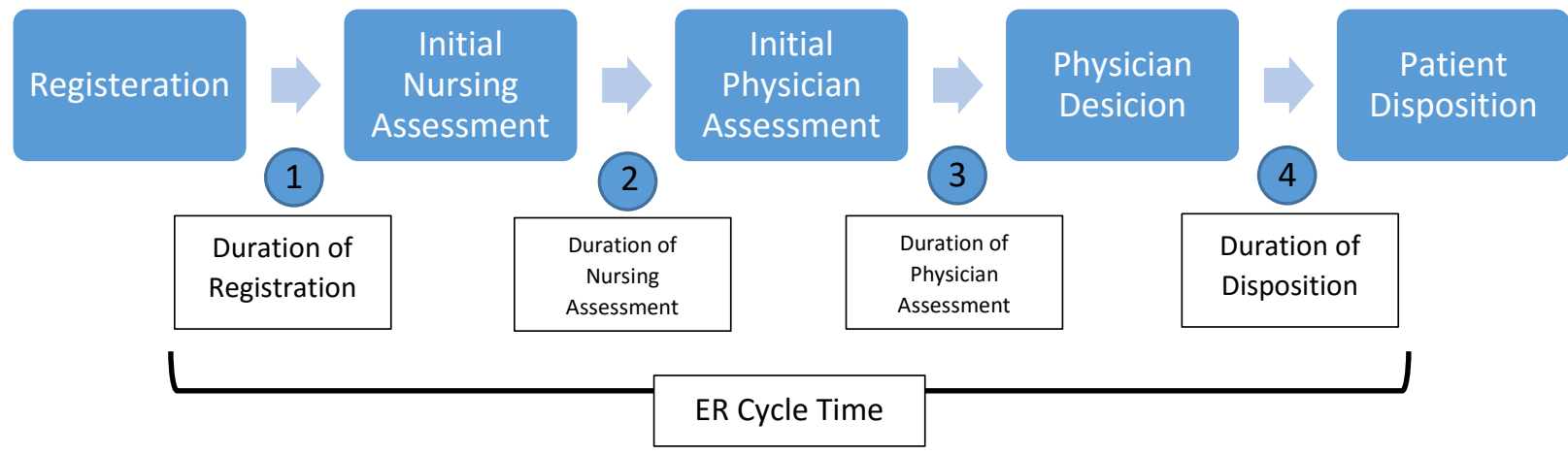

Figure (1)a high level flow chart of patient journey in emergency room. 